\title{
In the Space between Employees and Clients: The Impact of Organizational Context on a Refugee Program in Sierra Leone
}

\author{
LAKSHMI RAMARAJAN
}

\begin{abstract}
This paper uses a case-study approach to describe how organizational characteristics may influence program outcomes in humanitarian aid situations. Organizational structure and human resource management are discussed as organizational factors that influence the vulnerabilities of clients and employees. Interview and archival data from a program on reintegrating refugee and internally displaced women and girl survivors of sexual violence in Sierra Leone and observations based on the author's experience with the organization provides a relevant basis for isolating the firm as an important context within which refugee programs are embedded.
\end{abstract}

\section{Résumé}

Cet article utilise une approche d'étude de cas pour décrire comment les caractéristiques organisationnelles peuvent influencer les résultats de programmes dans des situations d'aide humanitaire. La structure organisationnelle et la gestion des ressources humaines sont examinées en tant que facteurs organisationnels ayant un impact sur les vulnérabilités des clients et des employés. Des informations provenant d'entrevues, ainsi que des données de documents d'archives, le tout faisant partie d'un programme du Sierra Leone pour la réintégration de femmes réfugiées et déplacées à l'intérieur des frontières et de filles rescapées de violences sexuelles, ajoutées aux observations issues de l'expérience de l'auteure au sein de l'organisation, fournissent un fondement pertinent pour désigner l'organisation comme contexte important où sont ancrés des programmes pour réfugiés.
$\mathrm{F}$ rom naïve (though dedicated) individuals committed only to "doing good," international humanitarian aid workers have evolved into sophisticated thinkers embracing the adjoining principle as well: "do no harm." However, the complexities of humanitarian aid ensure that "doing no harm" is not a simple, linear principle that merely needs to be implemented by individuals "on the ground." Both aid workers and clients are embedded in a web of organizations such as donors, competitors, governments, and collaborators that influence the vulnerabilities of clients both positively and negatively. The critical actor in the web of organizations is the actual NGO in which the aid worker is employed: the organization which is developing and administering the program for the clients. From a practical perspective, those who work in development organizations are aware of both the opportunities and limitations that working in their specific NGOs can provide. However, from a theoretical perspective, the actual role of the organization in influencing outcomes that both practitioners and theorists care about is not well understood. Becoming more aware of specific characteristics of NGOs doing humanitarian aid work is important because of the impact of these factors on the vulnerabilities of both aid workers and clients.

Research on NGOs in conflict currently tends to examine NGOs as group. Thus, Anderson's ${ }^{2}$ exhortation to "Do No Harm" targeted all NGOs operating in conflict and attempted to explain how NGOs in general could unintentionally affect conflict processes. Likewise, Aall ${ }^{3}$ and Last ${ }^{4}$ discuss NGOs as a group of players active in international conflict situations. More recently, Berinstain ${ }^{5}$ described the pros and cons of NGOs in humanitarian aid and development, again focusing on NGOs as a group of organizational players in the field of humanitarian aid. This emphasis on group-level characteristics and influence was important in 
the 1980s and 1990s as we observed the astonishing growth in NGOs as a class of organizations. ${ }^{6}$ However, it may now be opportune to turn attention, in both theory and practice, towards specific characteristics within the group of NGOs that can have important implications for workers and clients. Although most practitioners and researchers would acknowledge important differences among NGOs and accept that NGOs rarely act in concert and rarely have similar capacities and resources, there is little theory or empirical research on the particular characteristics of NGOs that might help explain project outcomes or their impact on peace.

This paper focuses on a single program within one organization to describe how organizational characteristics, specifically organizational structure and human resource management, interacted to influence the outcomes of a program to reintegrate women and girl survivors of sexual violence in Sierra Leone. The first section of the paper provides a brief background on the Sierra Leone conflict. The second section provides an introduction to the organization and the organization's program, which was targeted towards refugees and internally displaced women and girls. The third section reviews the data utilized to analyze program outcomes. Based on the data, it is argued that both organizational structure and human resource management issues are implicated in the implementation of the program. The implications of this case study are relevant to donors, NGO managers, and workers in humanitarian aid situations; organizational management can be a critical risk factor influencing clients' psychosocial outcomes and should be closely monitored and improved. The study also emphasizes the need for researchers on NGOs in conflict to begin examining organizational-level variables, such as structure, culture, and human resource management.

\section{Sexual Violence in the Sierra Leone Conflict: A Brief Summary}

The war in Sierra Leone lasted from about 1991 to 2002, with various coups and times of stability in those eleven years. In all, the war is thought to have resulted in about 50,000 dead. However, the number of refugees is about 400,000 and internally displaced persons (IDPs) anywhere from 300,000 (registered) to 1 million (unregistered). ${ }^{7}$ The number of IDP women suffering from war-related sexual assault is about 50,000 to 64,000 women; if one counts both war and nonwar related sexual assault, the estimates are over 200,000 women survivors. ${ }^{8}$ According to the same study, the prevalence rate of war-related sexual assault committed by combatants in Sierra Leone is 8 to 9 per cent. ${ }^{9}$

Carolyn McAskie, former United Nations Emergency Relief Coordinator, reported in April 2000 that team mem- bers of the United Nations Mission in Sierra Leone (UNAMSIL) deployed to the northern region of Sierra Leone were finding a higher incidence of women raped there than in Bosnia, where rape has been considered a war crime and where just recently sexual slavery was recognized as torture. In Sierra Leone, countless young girls and women were taken by combatants as sex slaves or "soldier's wives" and raped repeatedly for months or even years; these women have been subjected to astounding levels of sexual violence. In 2001, Human Rights Watch interviewed six women who had been raped and numerous more who were either held or taken away to rebel bases, for a time span varying from a few hours to several weeks. ${ }^{10}$ The pattern of gender violence has continued in the post-war situation as well. Returning combatants and other males highly traumatized by the years of constant exposure to violence and violent behaviour resort to sexual abuse and violence on the domestic front.

\section{Organizational Background: Training International}

Training International (TI ${ }^{11}$ is a US-based capacity building and sustainable development organization. Founded in 1970 by a leader in the civil rights movement, TI's mission is in the arena of human resource development, including skills training in vocational skills and agriculture as well as skills particular to the context of each country in which it works. TI is organized with a US-based headquarters and country affiliates. Unlike many other organizations, TI's country affiliates are independent, locally managed nonprofit organizations. In the last decade, due to the needs of TI affiliates in conflict-ridden countries, TI headquarters has provided assistance in conflict resolution, demobilization, and reintegration of ex-combatants, psychosocial counselling, and microcredit for those affected by war.

Traditionally, the local affiliates were the conduits for project management. People in the local communities knew of their TI chapter as a local skills training organization, not necessarily as the branch of an international organization. The staff and management of the local TI affiliate were long-term employees of the organization and local projects would be run by the local TI affiliate. International projects always came through the TI headquarters but were channelled through the local TI affiliate. The affiliates thus provided the access, knowledge, and manpower to implement the projects, while TI headquarters provided the international legitimacy and management so both the headquarters and the affiliate were able to access international aid money.

The affiliate in Sierra Leone, Sierra Leone Training International (TI-SL), has been established since the late 
1970s and currently has four training centres in different parts of the country. Traditionally, TI-SL offered training in skills such as carpentry, masonry, agricultural production, tailoring, and secretarial skills. In the early nineties, due to the outbreak of civil conflict in Sierra Leone and neighbouring Liberia, TI-SL with the assistance of TI has conducted demobilization, reintegration, and resettlement programs for ex-combatants, child soldiers, and war widows. From 1996, TI-SL began conducting training workshops to help prepare lay counsellors to assist persons severely affected by war in rebuilding their emotional and psychological health and their home communities. TI-SL has also emphasized agricultural and entrepreneurial training so individuals could learn to survive in the non-formal economy. In early 2000 TI-SL started offering shorter courses and extension services specifically for women and other vulnerable, displaced, and impoverished community members in rural areas.

\section{The Program: Reintegration of Women and Girl Survivors of Gender-Based Violence in Sierra Leone}

The program under study was initiated in 2003 by Training International, and funding was received from two US-based donor organizations. The program was intended to be a reintegration program for refugee and internally displaced women and girl survivors of gender-based violence in Sierra Leone. The design followed current best practices in offering psychosocial as well as economic assistance for refugees and the internally displaced. The program design consisted of three main components - skills training, business development training, and psychosocial counseling. The program was intended to run for one year with approximately six months of skills training and six months of business development assistance. Counselling would continue throughout the length of the program. ${ }^{12}$

The program took place in three locations, Bo, Mattru Jong, and Makeni. The participants were recruited through local organizations, using TI-SL's regular practices. There were seventy-five participants and in addition a trainingof-trainers workshop was held for thirteen female counsellors from local organizations working with survivors of sexual violence. Four counsellors were also appointed to the program. These counsellors were all Sierra Leonean women themselves and had considerable experience working with women and children who survived the war.

The general patterns of sexual violence and abuse discussed above were also reflected in the women who participated in this program. Of the seventy-five women who participated, twenty-five of the women, all from Mattru Jong, were forced to stay in rebel camps, from nine months to four years. Two-thirds of the Bo women stayed in camps, most from one to two years. For the Mattru Jong group, they experienced sexual abuse anywhere from several months to over a year. For the Bo group, abuse typically lasted several weeks, while for the Makeni group, abuse lasted over a year for most, but less than one week for some. Nearly all the women reported being either raped or gangraped, while molestation and sexual slavery were reported by about half of the women. ${ }^{13}$

\section{Program Outcomes}

This paper uses a single case study approach to understand the particular organizational influences in the organization on the program described above. The time period under study is from late 2002 to 2004 . During this time period, the program under study was initially proposed and launched. Data sources consisted of organizational documents related to the project including reports and correspondence sent to the donors, internal project evaluations that formed some of the source material for donor reports, internal correspondence regarding the project, and the original project proposal. Personal observations based on the author's experience with the organization and interviews with employees were also used to supplement this data. Given the sensitive nature of the data, and to protect confidentiality, all names of individuals and the organization have been altered.

The goal of this paper is not to use detailed and case-based information to generate theory. For that a much "thicker" description would be necessary. As a case study, the paper has the aim of generating discussion for practitioners and theorists about the importance of organizational- level factors in understanding humanitarian aid work. Examining closely the potential factors at an organizational level that may impede rather than enhance attempts at refugee assistance may be applicable to other organizations as well.

The major theme that emerged from the data regarding program outcomes was the extent to which the negative effects of the program were centred upon program management and administration rather than training or counselling. Overall, the outcomes of the program were largely seen as mixed; some positive but many negative impressions were conveyed by clients. The program had three sets of clients. First, TI-SL was a client of TI; second, the refugees and internally displaced women were the clients for TI-SL; and third, the counsellors for the women were also clients of TI-SL during an initial training program, before a few of them became employees.

The positive remarks noted about the program had to do with the actual training and counselling received. For example, during interviews with the refugee and internally 
displaced women in August 2003, the author found that many of the women were extremely positive about the opportunity to participate in the program. ${ }^{14}$ In a report to the donors:

None of the clients interviewed said they had any problems from the training or counseling. There was near unanimous agreement that counselors were helpful, trustworthy and extremely caring and supportive. In interview after interview clients expressed their appreciation for either the counselors or the training program itself. There was high satisfaction with the materials, curriculum and teaching method. Evidence of the women's grasp of their technical or life skills knowledge was reflected in several ways: (i) They wrote their names, knitted or told me of the basic execution of building a house in response; (ii) Many of the women interviewed directly made the connection between the counseling and their ability to learn and feel confident about taking control of their lives; and (iii) Many saw changes in their own confidence and abilities reflected in changes in the people around them, especially better treatment from their communities and families. ${ }^{15}$

For instance, in Bo, one participant mentioned that a few ex-combatants (who were also in the training centre) helped them out with lunch money ${ }^{16}$.

The counsellors who were interviewed also noted that they felt positively about their training and ability to work with women. Hawa, one of the counsellors, gave an example in the mid-term interviews of how she had been able to extend her work in her neighbourhood and help local couples where there is domestic abuse. Another counsellor gave the example of two women who felt that they could testify before the Truth and Reconciliation Commission after joining the program and talking to the counsellors. The counsellor counted this as a testament to the program's ability to help these women. ${ }^{17}$

However, the negative remarks all centred upon the financial obligation of the program to the clients. As many who work with refugees in situations of conflict understand, meeting basic needs is of primary importance in any program. Furthermore, keeping trust and meeting expectations lays the groundwork for the effectiveness of any program. However, as the excerpts below show, the lack of follow-through on the financial obligations to clients had a devastating effect on the program:

In August of that year:

The clients' major complaints were regarding financial support to help meet basic health needs; graduation ceremony expenses; and reintegration kits. ${ }^{18}$
Finally, the women all had questions regarding their reintegration kits. It was decided that these will be disbursed before the end of October. With these packages, the women can begin their self-employment activities, the final phase of this project. ${ }^{19}$

However, this last issue regarding the reintegration kits came up again later in the documents, at the end of October 2003 from the president of TI-SL.

This is a personal note requesting information on the Project. I sincerely wish to know what has happened or is happening that we cannot get the funds.... At the moment I am under a lot of pressure from all concerned, Trainees, Counselors and staff. I have run out of excuses to a point that I am even afraid and ashamed of going to the centres. [At] our last Board meeting ... the Trainees embarrassed me in the presence of Board Members that we have lied to them about resettlement kits.... The problem I have now is the unavailability of funds. Please, please treat this urgently [emphasis added]. ${ }^{20}$

And from the final report to donors:

Among the negative findings of the evaluation was the judgment that the project suffered from delays in fund transfers to TI-SL, and this was a shared managerial lapse both of TI-SL and of TI. In fact the lateness of reports from TI-SL meant that the last wire transfer to them occurred after the project's end date of September 30, 2003, despite the fact that project activities were ongoing. TI had known as early as February that the implementation schedule was behind, and requested a no-cost extension ... in July $30,2003 .^{21}$

As is apparent from the above quotes, two sets of clients, TI-SL and the program's participants, felt a severe impact based on the program management. For survivors of sexual abuse, violence, and war, trust is a critical issue. Prior work on conflict management is most emphatic on the importance of trust between aid workers and clients ${ }^{22}$ and the importance of this trust for conflict transformation. If participants felt they were deceived by the organization, this would erode the fragile trust between employees and clients, impeding the work of the organization and the positive impact of the program for the client. Second, the bond of trust and shared goals between TI-SL and TI is also impaired. Again, prior research on partnerships between Northern and Southern NGOs points to the importance of power and trust in the asymmetrical relationships between partners. $^{23}$

(C) Lakshmi Ramarajan, 2008. This open-access work is licensed under a Creative Commons Attribution-NonCommercial 4.0 International License, which permits use, reproduction and distribution in any medium for non-commercial purposes, provided the original author(s) are credited and the original publication in Refuge: Canada's Journal on Refugees is cited. 


\section{Organizational Characteristics: Structure and Human Resource Management}

The program evaluations above point towards two potentially important organizational variables at TI that could have influenced program implementation and outcomes in Sierra Leone. The first is TI's organizational structure. As is apparent from the quotes from the TI-SL president and the final report to the donors, TI-SL was dependent upon TI for program finances. This dependence on TI was a function of TI's organizational structure. Second, the sequence of escalating complaints about the finances from the no-cost extension in July 2003 to the president's humiliation and urgent request in October 2003 indicates TI's lack of managerial responsiveness to its clients. Both factors are further discussed below.

\section{TI's Organizational Structure}

The relationship between TI and the affiliate had an impact on the outcomes discussed above. Specifically, three related components of TI's relationship with the affiliate are relevant: (a) the size of the grant, (b) the absence of an expatriate, and (c) financial dependence of TI-SL.

TI's founding father was an icon in the civil rights movement and notions of partnership, justice, and equality were originally built into the movement organizations. This is why the affiliate structure was created and why the affiliates are independently run and managed organizations. That affiliates are TI's backbone has attained the status of myth. According to the myth, affiliate TIs were started only upon a request from local individuals, who had to gather an interest group representative of the community that wanted a local TI. Once the interest group was formed, TI and the interest group would both search for funding. The interest group was slowly developed into a board, which hired management and was independent of the TI board and management. TI would offer technical training and assistance to the local affiliate for a number of years and, once sufficiently institutionalized, the local TI affiliate would be a "graduate." Thus, TI affiliates and TI were meant to be partners in a common cause. However, over time this partnership came to mean different things to TI and the affiliates $^{24}$ and it also came to be practiced in different ways depending on the particular country affiliate and the specific programs being implemented.

One major defining structural factor was the size of the grant. Typically, large-scale programs, involving multimillion dollar, multiple year programs were funded by government aid organizations and other large donors. With large grant budgets came frequent travel and large vested interest in terms of TI's own survival and responsiveness to donor pressures to engage in frequent commu- nications with the affiliate. A second related feature was the presence of an expatriate TI international employee. Typically, TI international advisors were in-country for large-scale programs. When affiliate programs had expatriate advisors and large budgets, communication, travel between TI and the host country, and TI leadership attention were usually greater in frequency and quality and were also more likely to be sustained over time. On the other hand, communications, travel, and attention to programs in countries without the expatriate advisor and concomitant resources were usually not as well maintained. In the case of the TI-SL program for sexual violence survivors, this was a relatively small program in the overall budget of the organization (under US\$200,000). Thus, TI headquarters' resources, time, and leadership attention were rarely focused on the program. The third major feature of the program that was embedded in TI's organizational structure was the combination of managerial independence and financial dependence given to TISL. Given TI and TI-SL's history, TI-SL was an independent organization, even though TI still controlled the financial resources needed for implementation of the program. Strong separation of communication and managerial power between TI and TI-SL meant that communication between various functions (such as finance in the affiliate and finance at TI) and decision-making collaboration were not routinized. For example, the lack of communication paths between the affiliate TI-SL and TI can be noted in the need for a personal communication from the president of TI-SL. However, financially, TI exerted control over TI-SL's ability to implement the program.

On the one hand, expatriate managers come with their own set of problems in international humanitarian work. ${ }^{25}$ On the other hand, expatriate managers may have advantages in terms of their networks and understanding of parent organizations that allow affiliate programs to operate more effectively. Acknowledging and understanding some of the trade-offs that may come with affiliate programs and expatriate managers is necessary for organizations such as TI and its affiliates. It may be necessary to consider how to align the managerial and financial aspects of a program in order to improve effectiveness. For instance, when affiliates are not sufficiently independent in terms of managing their resources but are expected to be independent in terms of running their programs, this may result in tying affiliates' hands behind their backs and could impact the effectiveness of programs. Furthermore, the erosion of trust and imbalance of power between the local affiliate and headquarters could negatively influence future work by the parent organization and the self-efficacy of the affiliate. 


\section{TI's Human Resource Management}

The second aspect of the organizational context that may have influenced TI's diminished capacity to respond to its clients is its human resource practices. In humanitarian aid as well as other types of social service or non-profit work, recent research suggests that human resource management factors such as the lack of respect ${ }^{26}$ and justice ${ }^{27}$ employees feel they receive from their managers within the organization influence both employee burnout and client satisfaction. ${ }^{28}$ In a similar fashion, the reference above in the final report to donors to the "shared managerial lapse" may point to human resource management within TI that could have resulted in negatively affecting clients. Specifically, high turnover and leadership within the organization may have played a role in the organization's lack of responsiveness to clients.

During the time of the program (2002-2004), there were severe human resource management issues within the organization. Of the seventeen people employed by the organization in that time-frame, nine employees voluntarily resigned. That is a large exodus for a small organization to experience. Seven of the employees who left had been in program management, and two of them were senior executives. In addition, during this time, there were also numerous meetings and communications concerning employee dissatisfaction with management. ${ }^{29}$

The human resource management issues could have been the result of internal organizational changes. First, the founder of the organization has passed away in 2001. As research on organizational transitions shows ${ }^{30}$ the death of a founder has a profound effect on the organization. In the case of NGOs, research indicates that many NGOs rely on the presence of a charismatic founder-leader, ${ }^{31}$ and this may result in organizational failure once the charismatic founder is no longer present. ${ }^{32}$ Second, the organization itself was divided between a subgroup of newly hired "outsiders" in whom the history of the organization and its founder had not been inculcated and a subgroup of longserving "insiders" who had been part of the original movement and founding of the organization. For the latter, the cult of the charismatic leader and the routinization of charisma through rites, ceremonies, oral and written traditions engendered strong loyalty and identification with the founder and through that the organization ${ }^{33}$. For the former, it is likely that identification lay more with the profession of being an "aid" or "development" worker, rather than TI per se.

In the case of TI's more long-serving employees, the emphasis on loyalty to the leader could be due to the circumstances in which the movement and TI emerged. Lewis $^{34}$ notes that the context surrounding the formation of British and Swedish labour unions led to differences in the values that took hold in the organizations. British unions, forged in an environment of threat and distrust, valued insiders over outsiders, while Swedish unions were part of the national polity and were therefore more bureaucratic and professional. In a similar fashion, it is possible that the context of TI's founding affected the current values espoused within TI by the longer-serving group. The context could be important in several ways. First, given the civil rights movement and the atmosphere of social revolution that pervaded black organizations and communities, it is possible that loyalty in the guise of race became a primary value. ${ }^{35}$ Over time, although race was no longer so critical in the day-to-day development work of TI, the emphasis on loyalty was retained. Second, the founder's charismatic leadership when directly experienced results in the personal identification of followers with the leader. ${ }^{36}$ The direct experience of charismatic leadership is quite different from the experience created by the routinization of charisma because charismatic leadership typically induces reverence. ${ }^{37}$ One implication of this is that for the longer-serving members of the organization who revered and identified with the founder, personal loyalty to the leader could clearly have been part of the founding imprint of TI. Using the perspective of organizational blueprints, decisions made early in the life of the organization influence its later trajectory. ${ }^{38}$ When taken together, loyalty to the leader becomes taken as shorthand for loyalty to the cause as perceived by the individuals themselves.

On the other hand, as the organization expanded and hired individuals who had not been through its founding times or experienced the charisma of the founder directly, the balance of employees with loyalty to the leader within the organization changed. DiMaggio and Powell ${ }^{39}$ speak of professionalization and professional norms as causing isomorphism among organizations in an organizational field. That is, increasing professionalization, measured by hiring of individuals with academic credentials or positions in professional networks where organizational models are diffused, results in an organization resembling others in its field. The influx of new individuals who had worked in other organizations (and therefore belonged to a professional network) resulted in normative pressures on TI to change isomorphically regarding standards and norms of professional conduct. However, although DiMaggio and Powell ${ }^{40}$ state that professionalization may override the variations in tradition and control that shape organizational behaviour, the process of overriding itself could result in conflict. Similarly, if we consider the role of subcultures in an organization ${ }^{41}$ rather than organizational culture as one "shared meaning," we can see cul- 
tural conflict at TI between two subcultures: one promoting a professional organization and another promoting a loyalty-based system. Where loyalty and exchange built on loyalty shaped organizational and individual outcomes in the past, once professionalization began, organizational and individual outcomes were expected to occur based on professional norms. The transition in the organization and the conflicting expectations of both old and new employees may be partially responsible for TI's human resource management issues. As one former employee stated:

TI is on the brink of collapse due to the loss of program staff... we are struggling with program development, support and contractual needs as ONLY the three program VPs are $[$ left]... the staff whom we lost had years of in-house learning together with investment in their training through other opportunities. ${ }^{42}$

Both of these factors, the structural impediments to clear communication with and independence of the affiliate and the human resource management constraints, meant that programs, such as TI-SL's, suffered. The erosion of trust, both between TI-SL and the women and girl survivors of sexual violence in Sierra Leone and between TI and TI-SL, is likely to have left both sets of TI's clients in a more vulnerable position regarding recovery.

\section{Conclusions: An Opportunity for Learning}

This paper has tried to show through a case-study approach that both issues of organizational structure surrounding affiliate programming and issues of human resource management can influence program outcomes. The vulnerabilities of clients and employees in aid work are tied to the organizational contexts in which they are embedded. International programs are less able to be effective and clients are more likely to be disaffected when they are embedded in organizations with structural and managerial factors that act as impediments to effective program implementation.

Of course, one could ask whether it is not the responsibility of donor organizations to evaluate the extent to which NGOs have capabilities to execute successful programs. But as Church and Shouldice ${ }^{43}$ point out, the positive bias in evaluation occurs at all levels of conflict resolution programs. NGOs have a reason to put a positive spin on activities because of dependence on donor funding; program managers in the donor agencies have a reason to positively evaluate programs because they are judged based on grant performance; and donor agencies as a whole have a reason to put a positive spin on activities because they need to justify their funding from government sources to the public. The strength of the negative outcomes, as highlighted in this paper, would only be accessible from examining organizational records. Many authors on NGO performance argue that rather than project-based criteria for evaluations, learning should be the goal of project evaluation. ${ }^{44}$ This paper is not meant to be a project evaluation, but in the spirit of Edwards ane Hulme, ${ }^{45}$ it does point to opportunities for learning for both practitioners and theorists.

A vulnerabilities framework suggests that the organizational context, not just the program, country, or client factors should be included in an assessment of program impact. Future research that examines the role of NGOs on client outcomes in humanitarian aid and conflict situations should be cognizant of variables such as organizational structure, culture, and human resource management among others that may impact the vulnerabilities of clients. From a practitioner's perspective, NGO managers and employees may need to think carefully about their responsibilities to clients in terms of their own specific capacities for implementing programs. Understanding the structural and cultural context in which programs are embedded will help program managers and employees in NGOs figure out where the roadblocks and opportunities are within their organizations to improve their work with their clients.

Figure 1. Organizational Context Influences on Client Outcomes

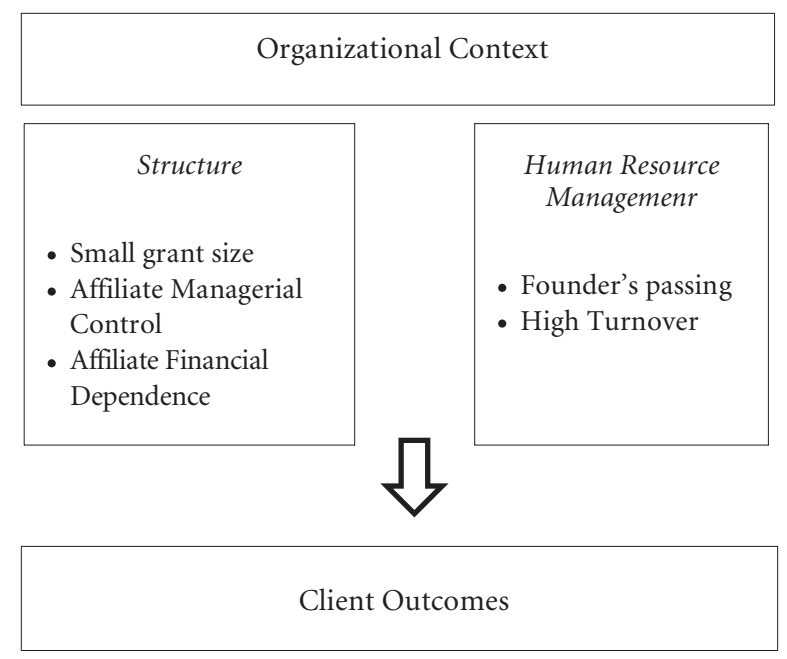

- Lack of delivery of resources

- Loss of trust with clients 


\section{Notes}

1. M. B. Anderson, Do No Harm: How Aid Can Support Peace Or War (Boulder, CO: Lynne Rienner, 1999).

2. Ibid.

3. P. Aall, "NGOs, Conflict Management and Peacekeeping," International Peacekeeping 7, no. 1 (2000): 121-141.

4. C. D. Last, "Organizing for Effective Peacebuilding," International Peacekeeping 7, no. 1 (2000): 8-96.

5. C. M. Berinstain, Humanitarian Aid Work: A Critical Approach (Philadelphia: University of Pennsylvania Press, 2006).

6. J. Boli and G. M. Thomas, "World Culture in the World Polity: A Century of Non-Governmental Organization," American Sociological Review 62, no. 2 (1997): 171-190; H. Teegen, J. Doh, and S. Vachani, "The Importance of Nongovernmental Organizations (NGOs) in Global Governance and Value Creation: An International Business Research Agenda," Journal of International Business Studies 35 (2004): 463-483.

7. L. Amowitz et al., "Letter from Sierra Leone: The Prevalence of War-Related Sexual Violence and Other Human Rights Abuses among Internally Displaced Persons in Sierra Leone," Journal of the American Medical Association 287, no. 4 (2002): 513-521.

8. Ibid.

9. Ibid.

10. Human Rights Watch, "No 'Safe Passage' through Rebel-Held Sierra Leone: New Plan Would Not Protect Refugees" (Freetown, Sierra Leone: Human Rights Watch, April 3, 2001).

11. The name of the organization and other identifying information have been changed to protect confidentiality

12. TI, Proposal to donors, September 2002.

13. TI, Summary of Participant Surveys, January 2003.

14. TI, Author's Trip Report, August 2003.

15. TI, Report to Donors, February, July, and November 2003 and March 2004.

16. Ibid.

17. TI, Author’s Trip Report, August 2003.

18. Ibid.

19. Ibid.

20. TI, Personal Correspondence from TI-SL Director, October 21, 2003.

21. TI, Report to Donors, February, July, and November 2003 and March 2004.

22. J. P. Lederach, Preparing for Peace: Conflict Transformation across Cultures (New York: Syracuse University Press, 1995).

23. S. Lister, "Power in Partnership? An Analysis of an NGO's Relationships with Its Partners" (International Working Paper No. 5, Centre for Civil Society, London School of Economics, London, 1999), <http://www.lse.ac.uk/collections/CCS/pdf/ IWP/int-work-paper5.pdf> (accessed March 25, 2008).

24. Ibid.; Lister discusses how the term "partnership" implies equalities between Northern and Southern NGOs that may not be the case in reality.

25. S.Mukasa, "Are Expatriate Staff Necessary in International Development NGOs? A Case Study of an International NGO in Uganda" (International Working Paper No. 4, Centre for Civil
Society, London School of Economics, London, 1999), $<$ http:// www.lse.ac.uk/collections/CCS/pdf/IWP/int-workpaper4.pdf $>$ (accessed March 25, 2008).

26. L. Ramarajan, L. S. Barsade, and O. Burack, "The Influence of Organizational Respect on Emotional Exhaustion in the Human Services," Journal of Positive Psychology: Special Issue on Positive Organizing (in press).

27. A. N. Garman, P.W., Corrigan, and S. Morris, "Staff Burnout and Patient Satisfaction: Evidence of Relationships at the Care Unit Level," Journal of Occupational Health Psychology 7, no. 3 (2002): 235-241.

28. M. Leiter, P. Harvie, and C. Frizzell, "The Correspondence of Patient Satisfaction and Nurse Burnout," Social Science Medicine 47, no. 10 (1998): 1611-1617.

29. Interviews with author.

30. M. Zald and R. Ash, "Social Movement Organizations: Growth, Decay and Change," Social Forces, 44, no. 3 (1966): 327-341.

31. J. Hailey and I. Smillie, Managing for Change: Leadership and Strategy in Asian NGOs (London: Earthscan, 2001).

32. M. S. Siddiqui, "Who Will Bear the Torch Tomorrow? Charismatic Leaders and Second-line Leaders in Development NGOs" (International Working Paper No. 9, Centre for Civil Society, London School of Economics, London, 2001), $<$ http://www.lse.ac.uk/collections/CCS/pdf/IWP/IWP9_NGO leadership-IWP.pdf> (accessed March, 25, 2008).

33. B. E. Ashforth and F. Mael, "Social Identity Theory and the Organization," Academy of Management Review 14, no. 1 (1989): 20-39.

34. D. Lewis, A. Bebbington, A. Batterbury, A. Shah, E. Olson, M. S. Siddiqui, and S. Duvall, "Practice, Power and Meaning: Frameworks for Studying Organizational Culture in Multiagency Rural Development Projects" (International Working Paper No. 12, Centre for Civil Society, London School of Economics, London, 2002), <http://www.lse.ac.uk/collections/ CCS/ pdf/ IWP/IWP12Lewis.pdf> (accessed March 25, 2008).

35. I thank Elijah Anderson, Sociology Department, University of Pennsylvania for this suggestion.

36. B. S. Pawar and K. K. Eastman, "The Nature and Implications of Contextual Influences on Transformational Leadership: A Conceptual Examination," Academy of Management Review 22, no. 1 (1997): 80-109.

37. J. A. Conger, R. N. Kanungo, and S. T. Menon, "Charismatic Leadership and Follower Effect,” Journal of Organizational Behavior 21, no. 7 (2000): 747-767.

38. A. L. Stinchcombe, "Social structure and organizations," in Handbook of Organizations, ed. J. G. March (Chicago: RandMcNally, 1965), 142-193.

39. P. DiMaggio and W. Powell, "The Iron Cage Revisited: Institutional Isomorphism and Collective Rationality in Organizational Fields," American Sociological Review 48, no. 2 (1983): $147-160$.

40. Ibid., 152.

41. Lewis et al.

42. Interview with author. 
43. C. Church and J. Shouldice, "The Evaluation of Conflict Resolution Interventions: Part I. Framing the State of Play," and "Part II: Emerging Practice and Theory" (Derry: INCORE [International Conflict Research], University of Ulster and United National University, 2002).

44. M. Edwards and D. Hulme, Beyond the Magic Bullet: NGO Performance and Accountability in the Post-Cold War World (London: Macmillan, 1995); A. Fowler, Striking a Balance: A Guide to Enhancing the Effectiveness of NGOs in International Development (London: Earthscan, 1997).

45. Ibid.
Lashmi Ramarajan is a candidate in the doctoral program in management at the Wharton School of Business, University of Pennsylvania. Her research centres on issues of identity and conflict in organizations, as well as management of non-profit organizations. Prior to joining the doctoral program, she received her MSc in international relations from the London School of Economics and worked on peacebuilding and post-conflict reintegration programs in West Africa. The author would like to thank the employees and managers of TI and TI-SL and the participants of TI-SL's program in Sierra Leone.

(C) Lakshmi Ramarajan, 2008. This open-access work is licensed under a Creative Commons Attribution-NonCommercial 4.0 International License, which permits use, reproduction and distribution in any medium for non-commercial purposes, provided the original author(s) are credited and the original publication in Refuge: Canada's Journal on Refugees is cited. 